\title{
First record of avian cestode Variolepis podicepsi n.sp. from Podiceps rufficolis (Pallas) from J hansi, U.P., India
}

\author{
A. K. Srivastav ${ }^{1}$, V. K. Sahu² and Pragya Srivastava ${ }^{3}$ \\ ${ }^{1}$ Parasitological Laboratory, Department of Zoology, B.B. (P.G.) College, Jhansi (U.P.), INDIA \\ ${ }^{2}$ Department of Zoology, J.N.R.M., Port Blair, A \& N Island, INDIA \\ ${ }^{3}$ Department of Zoology, Chitransh Degree College, Bhopal (M.P.), INDIA \\ *Corresponding author. E-mail: viveksahu6@ rediffmail.com
}

\begin{abstract}
Twenty eight cestodes were obtained from three little grebs, Podiceps rufficolis (Pallas) from Jhansi. Morphological studies of the cestodes revealed that they belonged to the genus, Variolepis Spasskii and Spasskaja, 1954 of the sub family Hymenolepidinae Perrier, 1897 family Hymenolepidae Ralliet and Henery, 1909 and regarded as n.sp Variolepis podicepsi.
\end{abstract}

Keywords: Greb, Jhansi, Podiceps rufficolis, Variolepis podiceps n.sp, Tapeworm

\section{INTRODUCTION}

Birds are invariably infected by a large number of Parasites. Among the parasite that infect, Helminth, represented by 5 well characterized taxonomic units, Cestoda, Trematoda, Nematoda, Monogenoidea and Acanthocephala, form a major group and often cause veterinary problem world wide (William and Jones, 1994). Helminth parasites are important not only because they cause human and other vertebrate disease but also because they are an essential component of global biodiversity (Poulin, and Morand, 2004). These parasites constitute more than half of the biodiversity (Toft, 1986). During the study on avian cestodes in Jhansi, we come accidentally killed little grebs, Podiceps rufficolis (Pallas) was collected and specimens were from obtained intestines.

\section{MATERIALS AND METHODS}

The intestines were removed from hosts and cut open into saline water. It lightly shaken and content decanted several times and thoroughly examined under the simple microscope. The parasites were found attached in the mucosa by its scolex. Worms were strached in the lukewarm water with help of fine brush and later fixed in $5 \%$ formalin. Whole mounts were stained in Mayer's haemalum and cleared in xylol. Camera lucida drawings were made. All the measurements in millimeters unless otherwise stated.

\section{RESULTS}

Cestodes measure $75-105 \mathrm{~cm}$ in length and 0.53 in maximum breadth as seen in gravid proglottids. Gravid proglottids broader than long and craspedot. Scolex measures $0.14-0.25 \times 0.072-0.23(0.18 \times 0.15)$. Suckers Four, oval to round, unarmed, measures $0.042-0.078 \mathrm{X}$ $0.042-0.072$ ( $0.060 \times 0.057)$. Rostellum armed, measures $0.066-0.20$ X $0.064-0.090$ ( 0.135 X 0.082). Rostellar hooks ten in number, arranged in a single row measure $0.058-0.064$ (0.068) in length. Handle $0.032-0.040(0.036)$; guard $0.016-0.026(0.024)$ and blade $0.021-0.030(0.028)$ in length. Neck measure $0.35-0.39 \mathrm{X} 0.13-0.16(0.37 \mathrm{X}$ $0.14)$. Immature proglottids measure $0.018-0.030 \mathrm{X} 0.18$ - 0.35 ( $0.024 \times 0.26$ ); mature proglottids measure 0.048 $0.072 \times 0.350 .44(0.060 \times 0.40)$ and gravid proglottids measure $0.072-0.096 \times 0.43-0.53(0.084 \times 0.48)$. Testes three in number in which one poral and two aporal, oval to round measure $0.012-0.015 \times 0.015 \times 0.012-0.021$ $(0.014 \times 0.018)$. Cirrus pouch elongated measure 0.22 $0.29 \times 0.012-0.030(0.25 \times 0.021)$ and ventral longitudinal excretory canal up to the $2 / 3^{\text {rd }}$ of the proglottids width. Cirrus armed, measure 0.030-0.078 X 0.006-0.012(0.054 $X$ 0.009). Internal and external seminal vesicles absent. Female genitelia slightly aporal. Ovary bilobed measure $0.006-0.012 \times 0.042-0.072(0.009 \times 0.057)$. Vitelline gland post ovarian compact $0.006-0.009 \times 0.018-0.024(0.008$ $\mathrm{X} 0.021)$. Vagina posterior to cirrus pouch measure 0.006 -0.015 (0.011) in diameter. Receptaculum seminis measure $0.018-0.036 \times 0.006-0.012(0.027 \times 0.009)$. Genital atrium measure $0.006-0.018(0.012)$ wide and $0.006-0.030(0.018)$ in deep. Genital openings unilateral and located in the anterior half of the proglottid margin. Uterus sac like measure $0.036-0.072 \times 0.35-0.45(0.054 \times 0.40)$, extended beyond the limits of ventral longitudinal excretory canals. Eggs measure 0.008-0.016 X 0.008-0.019 (0.012 X 0.014). Onchospheres measure $0.0064-0.011$ X $0.008-0.013$ (0.009 X 0.010). Ventral longitudinal excretory canals 

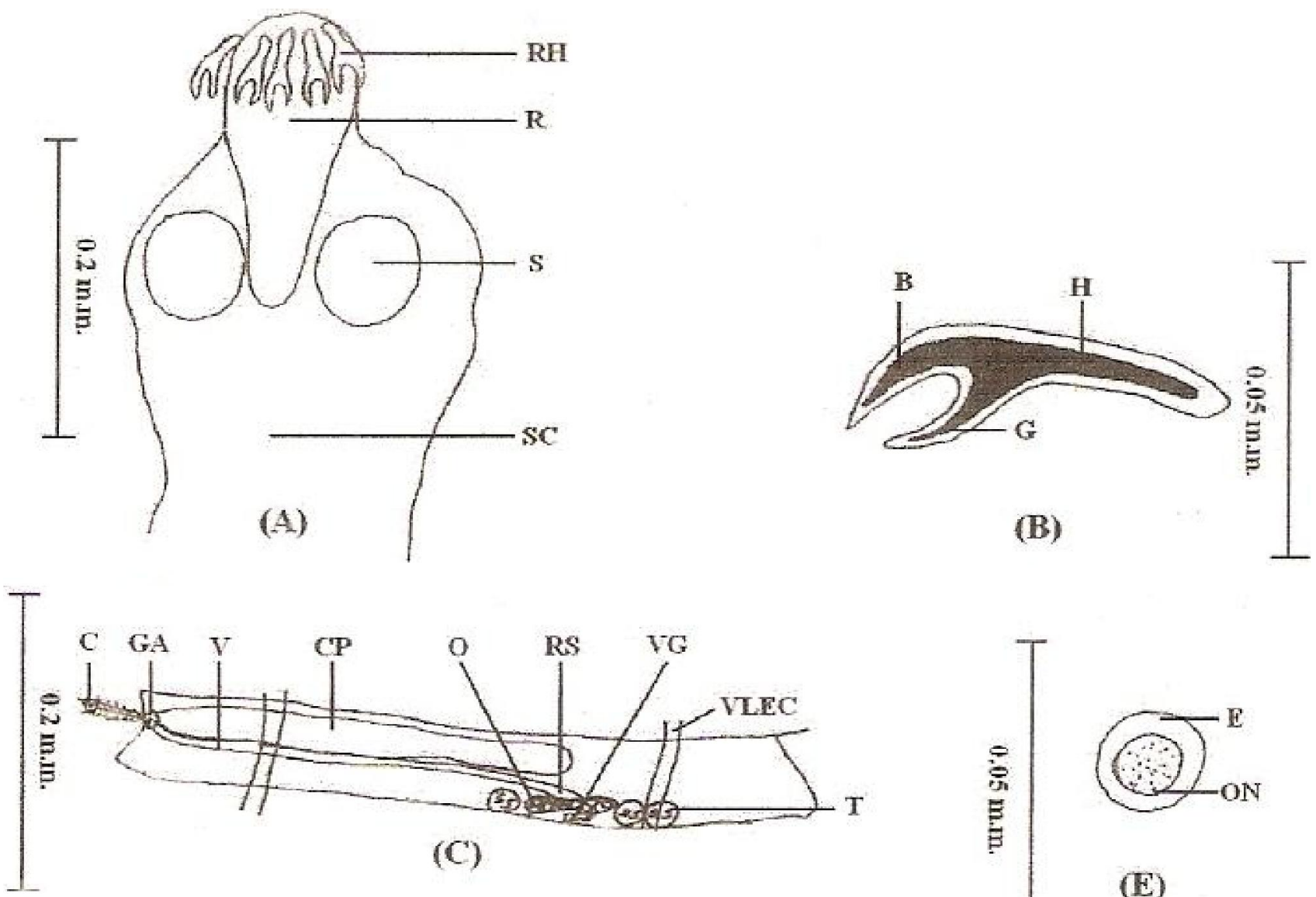

(C)
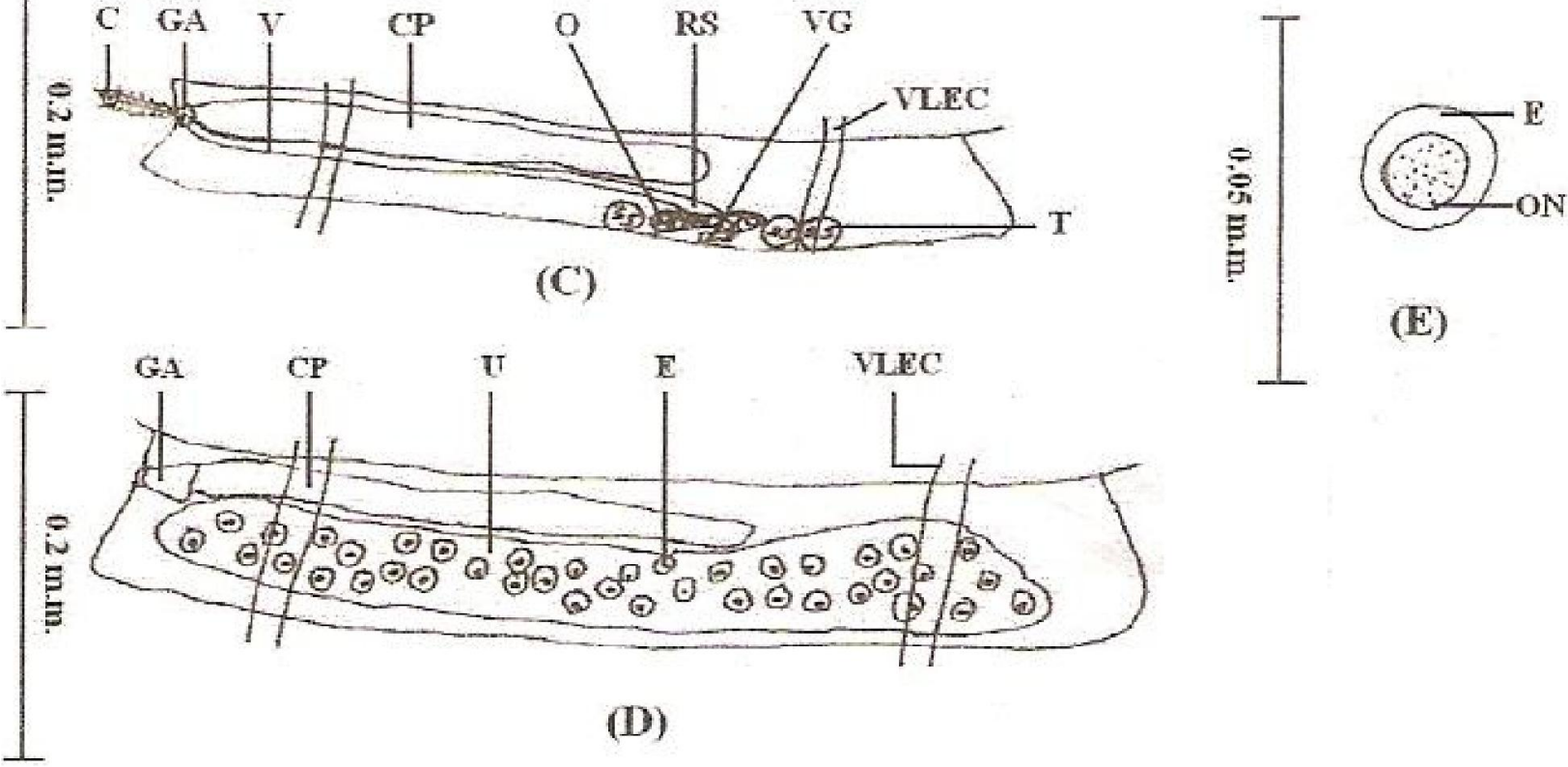

(D)

Fig.1. Variolepis podicepsi n. sp. (A) Scolex $(100 \mathrm{X})$, (B) Rostellar hooks $(450 \mathrm{X})(\mathrm{C})$ Mature proglottid (100 X), (D) G ravid proglottid (100 X), (E) Egg (450X). A bbreviations: B - Blade, C- cirrus, CP-Cirrus Pouch, E - Egg, G - guard, GA - Genital atrium, $\mathrm{H}$ - Handle, $\mathrm{O}$ - O vary, ON - Onchosphere, R - Rostellum, RH - Rostellar Hooks, RS - Recetaculum seminis, S - Sucker, SC - Scolex, T - Testes, U - U terus, V - Vagina, VG - Vitelline gland, VLEC - Ventral longitudinal excretory canal.

measure $0.006-0.018(0.012)$ in diameter.

\section{DISCUSSION}

The present form comes closer to Variolepis planestici (Mayhew, 1925) Spasskii and Spasskaja, 1954; V. victoriata (Inamdar, 1934) Spasskii and Spasskaja, 1954; V. hughesi (Yamaguti, 1959), V. variabilles (Mayhew, 1925) Yamaguti 1959; V. passerus Tiwari, 1987 and V. tritis Tiwari, 1987.

From V. planestici (Mayhew, 1925) Spasskii and Spasskaja, 1954, the new species differs in having Larger worm, longer rostellar hooks, narrower testes, different shape of ovary, narrower eggs and narrower onchospheres.From V. victoriata (Inamdar, 1934) Spasskii and Spasskaja, 1954, it differs in having narrower worm, larger rostellar hooks, wider testes, different extension of larger cirrus pouch, different shape of narrower ovary, smaller eggs and narrower onchospheres.

From V. hughesi Yamaguti, 1959, it differs in having longer worm, larger rostellar hooks, smaller testes, narrower cirrus pouch, different shape of smaller ovary, smaller vitelline gland, narrower eggs and narrower onchospheres. From V. variabilles (Mayhew, 1925) Yamaguti 1959; it differs in having smaller worm, wider 


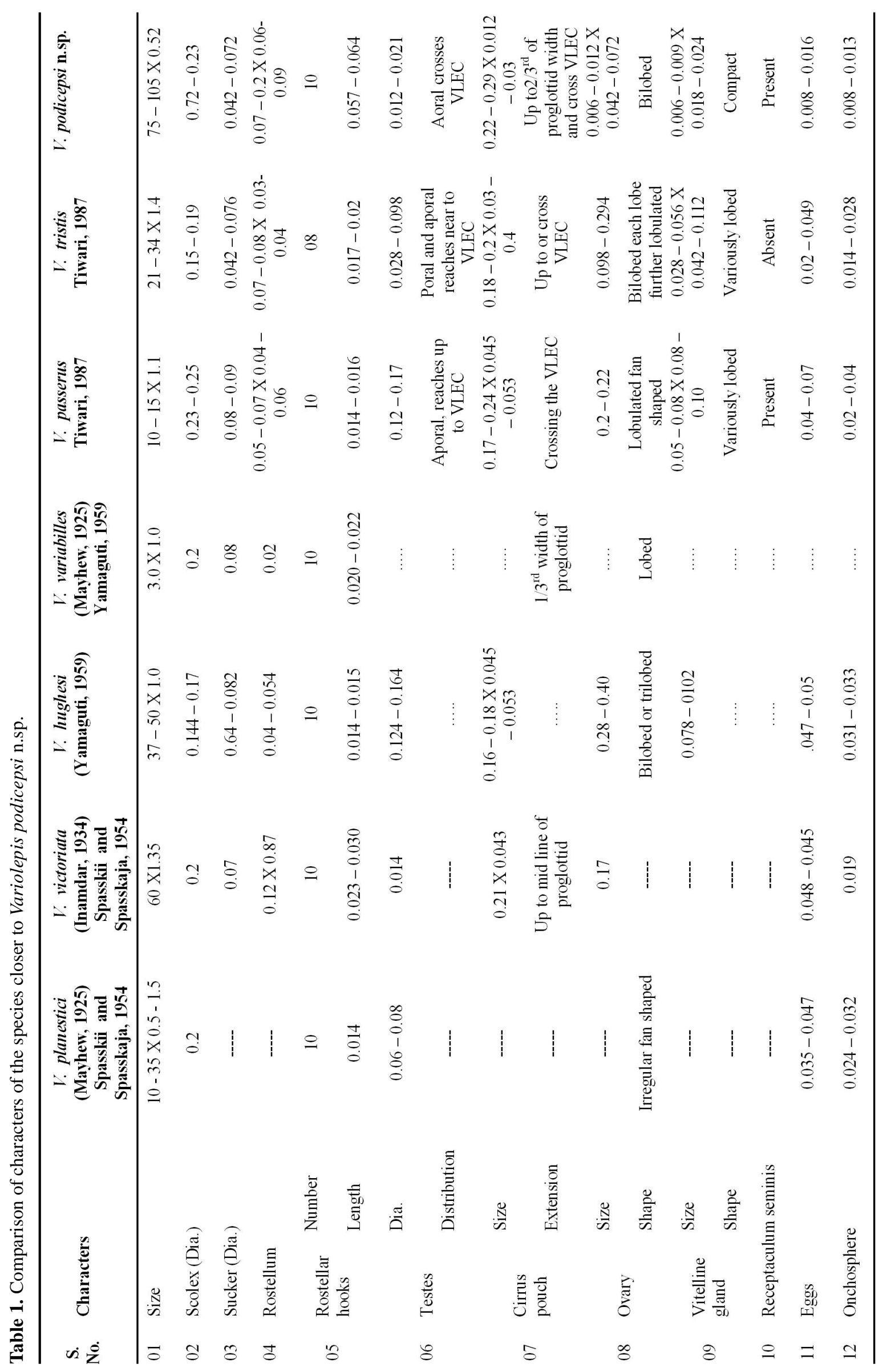


rostellum, larger rostellar hooks, different extension of cirrus pouch, and different shape of ovary.

From V. passerus Tiwari, 1987, it differs in having larger worm, longer rostellar hooks, smaller testes, narrower cirrus pouch, bilobed narrower ovary, compact smaller vitelline gland, smaller vitelline gland, smaller eggs and smaller onchospheres. From V. tritis Tiwari, 1987, it differs in having larger wider rostellum, greater number of larger rostellar hooks, narrower testes, different extension of cirrus pouch and different shape of ovary (Fig. 1 and Table 1).

In the light of above discussion,the present form has been regarded as a new species Variolepis podicepsi $n$. sp.

Type species

Host

Habitat

: Variolepis podicepsi n. sp.

Locality : Podiceps rufficolis (Pallas)

Number of

Deposition : Parasitological loboratory, Department of Zoology, B.B. (P.G.) College, Jhansi (U.P.) India.

\section{ACKNOW LEDGEMENT}

Authors are thankful to Prof. A.K. Chopra, Department of Zoology and Environmental Science, Gurukula Kangri
University, Haridwar (UK) four pertinent encouragement during the preparation of manuscript.

\section{REFERENCES}

Inamdar, N. B. (1934). Four new species of avian cestodes from India. Zeitschr. Parasit., 7: 198-206.

Mayhew, R.L. (1925). Studies on the avian species of the cestode family Hymenolepidae III, B il. M onogr. 10: 1-125.

Perrier, E. (1897). Classification des cestodes. Comt. Rend. Acad. Sc. 86: 552 - 554.

Poulin, R. and Morand, S. (2004). Parasite Biodiversity (Washington, DC: Smithsonian Institution Books) pp. 216.

Ralliet, A. and Henery, A. (1909). Les cestodes du Blaireau (Meles Taxus). Compt. Rend. Soc.Biol. 53: 23 - 25.

Spasskii. A.A. and Spasskaja, L.P. (1954) Systematic structure of the Hymenolepidae Parasites in birds (In Russian) Tr. Helminthol. Lab. A kad. Nauk. SSSR, 7: 55 - 119.

Tiwari, J. P. (1987). Studies on morphology and taxonomy of certain cestodes. Ph. D. Thesis, Bundelkhand Univ. Jhansi; 1- 205.

Toft, C.A. (1986). Communities of Parasites with Parasitic life style; in Community Ecology (eds) J. M. Diamond and TJ Case (Hasper and row). pp. $445-463$.

William, H.H. and Jones, A. (1994). Parasitic Worms of Fish (London: Taylor and Francis). pp. 593.

Yamaguti, S. (1959). Systema Helminthol. The cestodes of vertebrate. Vol. 2, Interscience, Newyork, 1- 860. 